\title{
NEED OF SUSTAINABLE DEVELOPMENT AND RELATED ISSUES PERTAINING TO PROCESS INDUSTRY
}

\author{
Jitendra Kumar ${ }^{1}$, Shikha Gangil ${ }^{2}$, Chanchal Mewar ${ }^{3}$, Bharat Modhera ${ }^{4}$ \\ ${ }^{1}$ Chemical Engineering Department, Maulana Azad National Institute of Technology, Bhopal, India-462 051 \\ ${ }^{2}$ Chemical Engineering Department, Maulana Azad National Institute of Technology, Bhopal, India-462 051 \\ ${ }^{3}$ Chemical Engineering Department, Maulana Azad National Institute of Technology, Bhopal, India-462 051 \\ ${ }^{4}$ Chemical Engineering Department, Maulana Azad National Institute of Technology, Bhopal, India-462 051
}

\begin{abstract}
Main aim of human body needs use is an ideality resource of sustainable development to while salvation the environment. So their needs are not limited only in the present, it's also needed for next generations. Sometimes taught as Environment, Local people, Future. Past some years, Sustainable Development has escape as the latest development. The new examples of development has accept that a large range of non-governmental as well as governmental organizations like any nation in the world. Chemical and chemical industries are facing challenge of the sustainability development in the world. This review paper studies is about chemicals and sustainable development in overall coming of the world. It includes an incomplete comprise of the problems of chemicals and environmental degradation, mainly economic growth and the concepts of sustainability are confusion role in the environment.
\end{abstract}

Keywords: Brundtland commission, Sustainable development, Sustainability, Life cycle analysis.

\section{INTRODUCTION}

According to Brundtland report (1987): the proposal of sustainable development being generated universally. "Development that meets the needs of the present without compromising the ability of future generations to meet their own needs"[1]. Sustainable Development has two main proposals:

- The idea of 'urgent needs' of the world's poor, to which overruling dominance should be given; and

- For future aspect, the state of technology and social society with institutes forced the concept of limitations on the environment's potentiality. Sustainable development is a gracious idea, as a broad array of views comes under this category.

\section{SUSTAINABILITY IN ENGINEERING}

\subsection{Engineering Roles \& Functions}

In present the limits becoming obvious and the old industrial pattern of unlimited growth is unsustainable, in old pattern it requires endless use of fixed resources, and endless environmental capacity. Engineering consider those terms is also unsustainable. To achieve the target of sustainability, we need sustainable engineering because Engineers play a vital \& strategic role in making the world's infrastructure as well Engineers are capable to do projects that meet human needs. Engineers are able for solving the problems and they are also capable to do work on a broad range of issues and projects, so engineers give their best to overcome the problem of unsustainability with the help of projects which conserve natural resources, economic, and support human and natural environments. An engineer can apply his knowledge and experience in designing and creating projects that meet basic human needs and able to solve environmental problems.

\section{HISTORY OF SUSTAINABLE DEVELOPMENT}

\subsection{The Limits of Growth}

The study entitled "The Limits to Growth," which was used to simulate tomorrow outcomes of the world economy by largescale computer model. The authors predicted that, the world development changes within 100 years would have occur only if there would be major changes in the physical, economic, or social relationships, society will demand renewable resources on which industry are not depending. This would help to overcome the destroying factors which are brought by huge unemployment, less food production, which is due to increasing population and decreased [2]. They warned that the destruction can be controlled by avoiding by increased population and pollution, as well as economic growth.

\subsection{The Brundtland Report}

In 1987, a report which paying attention about the environment and poverty in many parts of the world which is 
wide spreading. According to Brundtland report economic development cannot stop, but it should change in a manner which is favorable for planet's ecological limits [3].

\section{CRITICAL ISSUES}

- In developing countries, chemical industries consumption and production are growing much faster in comparison to developed countries and can be notice as a third global consumption by 2020 .

- The construction minerals and ores/industrial minerals extraction increased by a factor of 34,27 , while biomass extraction grew by 3.6 times in the past century.

- High conservation value area is located by 10 percent of dynamic mines and 20 percent of investigative sites approximately, while water-stressed areas are located by 30 percent of active mines.

- In 2000 and $2005, \mathrm{CO}_{2}$ emissions is increased by 12 percent from transport, twice the rate for buildings, but the emissions from electricity generation and industry is less.

- Hazardous electronic or electrical products are the content of chemical industries waste as growing share. E-waste is growing approximately 3-5 per cent per annum in Europe.

- In risk assessments, number of chemicals released by undertaken chemical industry is multiplied by seven times in 2001 to 2009 compared the period between 1995 and 2000 [4].

\subsection{Biodiversity Loss}

Biodiversity is in dangerous condition because various chemical and other wastes, toxics etc, released by chemical industries. So now there's a time to continuously watch these threats. UN Conference on Environment and Development in 1992, the Convention on Biological Diversity was start along with 192 countries in addition of European countries. The Parties (April 2002) to the Convention assigned to extensively reduce the biodiversity loss by 2010. Many successful preservation procedures favors biodiversity in spite of, the biodiversity target (2010) has not been met universally [5].

\subsection{Energy Security}

A rising alarm for wealthy and emerging countries is Energy Security. In olden ages, fossil fuel energy has led to wars, bring down of democratically nominated leaders, and puppet governments and their autocracy. Various chemical industries should consider energy security. Foremost countries declared that oil is essential part of life, but savings for alternative fuels in process industries has been deficient, or very less. Worldwide financial crisis takes hold and alertness of environment change. Most of countries and companies are trying their best to spend in process industries alternatives.

\subsection{Environmental Issues}

Environmental issues arises due to chemical industries because Chemical industries also a vast universal problem. Undoubtedly Chemical industries and many other chemical processes aim to depend on a sustainable and hale and hearty environment, and so far we have smashed the environment in several ways. Environmental issues associated to chemical industries, initiate other issues together with biodiversity, climate change, animal and nature preservation, population, hereditarily customized food, sustainable development.

\section{NEED OF THE HOUR}

This is the century of the economic boom. India itself has seen a growth rate of 9 per cent in the previous financial year. There is a hurry to obtain as many benefits in as little time as possible. Production capacity should be to escalate and profits to huge for the industrial sector, manufacturing sector, infrastructural sector, etc. The demands of developing and developed countries need the manipulation of natural resources. No economy can stay alive without coal, petroleum, electricity, wood and steel, because of all these are essential commodities for the society. Industries could not run until they are fed these precious and stealthily depleting resources. In the present time, the world has become aware of how these resources are fast depleting. If these resources are not utilized efficiently, soon a day will come when next generations will not even have drinking water. Sustainable development is not need just for the environmental benefits, but it is the economic benefits. Governmental processes and judgment means to sustainable development due to chemical industries.

\subsection{World Summit on Sustainable Development}

\section{Johannesburg, South Africa (26th August - 04th} Sept., 2002)

Renew the devolution to sound management of chemicals released must followed by chemical industries. It is a life cycle and as well as protection of human health and environment. According summit discussion to achieve up to 2020, that chemical is used and produced in ways that guidance to the minimization of considerable adverse effects on human health. On the base of risk assessment and management procedures, transparency should be used by the environment. That would be including actions at all levels:

(a) Endorse the corroboration and implementation of relevant worldwide instruments on chemicals and hazardous waste, including the Rotterdam Convention on Prior Informed Consent Procedures for Certain Hazardous Chemicals and Pesticides in International Trade so that it can enter into force by 2003 [6].

(b) Develop a strategic approach to international chemicals management based on the Bahia Declaration and Priorities for Action beyond 2000 of the Intergovernmental Forum on 
Chemical Safety by 2005. And instance that the United Nations Environment Program, the Intergovernmental Forum and other international organizations dealing with chemical management and other relevant international organizations [7].

(c) Promote countries to implement the new universal harmonized system for the classification and labeling of chemicals as soon as possible with a view to having the system fully operational by 2008 .

(d) Encourage partnerships to promote activities aimed at enhancing environmentally sound management of chemicals and hazardous wastes. And implementing multilateral environmental agreements, raising awareness of issues relating to chemicals and hazardous waste and encouraging the collection and use of additional scientific data.

(e) Promote efforts to intercept international illegal trafficking of hazardous chemicals and hazardous wastes. To prevent damage resulting from the transboundary movement and disposal of hazardous wastes in a manner consistent with obligations under relevant international instruments. Such as the Basel Convention on the control of transboundary movements of hazardous wastes and their disposal.

(f) Promote development of coherent and integrated information on chemicals, such as through national pollutant discharge and transfer registers

\section{CURRENT TRENDS IN SUSTAINABLE ENGINEERING}

\subsection{Life Cycle Analysis (LCA)}

In 1960s, LCA was originated; it evaluates the environmental consequences of a product or process over its entire life. The Environmental Protection Agency (EPA) defines the stages of a life cycle as follows [8-10]:

- Raw Materials Acquisition involves extracting raw materials and energy sources from the earth and transporting them to their processing locations.

- Manufacturing involves the production from raw materials and sent for delivery to consumers, the conversion of the raw material into product (a form in which it can be used) is termed as materials manufacture.

- Fabrication is the method of producing material into a product that can be used as packages by itself distribution includes filling, packaging and transportation to accomplish these tasks.

- Use/Reuse/Maintenance is the actual area of product, when reuse and maintenance might be required and energy is required by storage and consumption.

- Recycle/Waste Management includes final product disposition with the waste and energy requirements.

- Energy consumption requires transportation and waste management practices which are carefully measured at all stages of life cycle.

\section{CONCLUSIONS}

Sustainable development is an important step to the upcoming attainment of process industries and society. It forms a primary basis for future focused commercial governance. An area of sustainable development is focused by Health, Safety Quality and Environment. To retain sustainable growth of the process industry, there is a need for uniform standards in environmental management across the world. Every corporate business must be endowed with tools to monitor measure and enumerate the allegation on the environment and risks in its areas of operation. To sustain utilization of natural resources, environmental guidelines need to be developed on the basis of industrial work practices. An association needs to make constant efforts to diminish consumption of renewable resources, and extend dynamic ways of reuse and recycle the waste resources. Ecological audits are approved out in a periodic means to ensure the level of emissions and the constituents of the waste items disposed.

\section{REFRENCES}

[1] United Nations: reports on - World Summit on Sustainable Development Johannesburg, South Africa Johannesburg Plan of Implementation. 26 Aug. - 4 Sep. (2002).

[2] UN Commission on Sustainable Development $5^{\text {th }}$ Session New York, Resolution Adopted By the General Assembly for the Programme for the Further Implementation of Agenda. 725 April. (1997).

[3] UN Commission on Sustainable Development 3rd Session New York. 11-28 April. (1995).

[4] UN Commission on Sustainable Development 2nd Session New York. 16- 27 May. (1994).

[5] M. Golusin, M.O. Ivanovic, N. Teodorovic, The review of the achieved degree of sustainable development in South Eastern Europe-The use of linear regression method, New York, Elsevier. (2011).

[6] Division for Sustainable Development. Indicators of Sustainable Development: Guidelines and Methodologies, Washington: United Nations, UNCED. (2001).

[7] J.R. Katzer, Sustainable Research Development and Demonstration (R\&D), America: American Chemical Society. (2010).

[8] K. S. Subhas, Sustainability Perspective and Chemistrybased Technologies, America: American Chemical Socity. (2007).

[9] L. L. Rebecca, T. A. Paul, Life-cycle Approaches for Assessing Green Chemistry Technologies, America: American Chemical Society. (2002).

[10] R. Ramanathan, L. S. Ganesh, Energy Resource Allocation Incorporating Qualitative and Quantitative Criteria: An Integrated Model Using Goal Programming and AHP, New York: Elsevier. (1995). 